\title{
Evaluasi Terhadap Pelaksanaan E-Warong Di Kecamatan Padangsidimpuan Tenggara
}

\author{
Rahayu', Aliman Syahuri Zein² \\ 1,2,3Institut Agama Islam Negeri Padangsidimpuan
}

JL. H.T. Rizal Nurdin Km 4,5 Sihitang Kota Padangsidimpuan - Sumatera Utara

E-mail: rahayuajah874@gmail.com, alimansya@iainpadangsidimpuan.ac.id

\begin{abstract}
Abstrak
Salah satu permasalahan yang sering dialami oleh negara berkembang adalah masalah kemiskinan, tidak terkecuali negara Indonesia. Sebagai upaya percepatan penanggulangan kemiskinan, sejak tahun 2007 Pemerintah Indonesia telah melaksanakan (Program Keluarga Harapan) $\mathrm{PKH}$, dimana di dalamnya terdapat rancangan program E-Warong (Kelompok Usaha Bersama) KUBE PKH sebagai sarana mempercepat pengentasan kemiskinan. Penelitian ini bertujuan untuk mengevaluasi pelaksanaan E-Warong KUBE PKH. Penelitian ini merupakan penelitian kualitatif, sumber data adalah data primer dan data sekunder. Hasil penelitian ini menunjukkan bahwa evaluasi terhadap pelaksanaan E-Warong KUBE PKH di Kecamatan Padangsidimpuan Tenggara belum maksimal dilakukan sesuai dengan petunjuk pelaksanaan E-Warong KUBE PKH, terdapat beberapa faktor yang menyebabkan pelaksanaan E-Warong KUBE belum maksimal dilaksanakan diantaranya, kurang kesadaran anggota $\mathrm{PKH}$ terhadap tanggungjawab E-Warong KUBE yang menyebabkan E-Warong KUBE belum bisa dikatakan berhasil dalam peningkatan perekonomian bersama dan kurangnya pemahaman anggota $\mathrm{PKH}$ dalam menggunakan teknologi khususnya dalam penggunaan mesin gesek. Adapun kontribusi dalam penelitian ini diharapkan agar pihak EWarong KUBE PKH mampu untuk mengevaluasi program supaya berjalan dengan baik dan untuk memperbaiki kinerja dari setiap anggota PKH kedepannya.
\end{abstract}

\section{Kata Kunci: Evaluasi, Pelaksanaan, E-Warong KUBE PKH.}

\section{Abstract}

One of the problems often experienced by developing countries is the problem of poverty, including Indonesia. As an effort to accelerate poverty reduction, since 2007 the Government of Indonesia has implemented the PKH (Family of Hope Program), in which there is a design for the E-Warong (Joint Business Group) KUBE PKH program as a means of accelerating poverty alleviation. This study aims to evaluate the implementation of $E$ Warong KUBE PKH. This research is a qualitative research, the data sources are primary data and secondary data. The results of this study indicate that the evaluation of the implementation of E-Warong KUBE PKH in Southeast Padangsidimpuan District has not been maximally carried out in accordance with the instructions for implementing $E$ Warong KUBE PKH, there are several factors that cause the implementation of E-Warong $K U B E$ has not been maximally implemented including, lack of awareness of PKH members towards the responsibility of E-Warong KUBE which causes E-Warong KUBE cannot be said to be successful in increasing the common economy and the lack of understanding of PKH members in using technology, especially in the use of friction machines. As for the contribution in this research, it is hoped that the E-Warong KUBE PKH will be able to evaluate the program so that it runs well and to improve the performance of each $\mathrm{PKH}$ member in the future. 


\section{PENDAHULUAN}

Suatu negara tidak terlepas dari berbagai macam permasalahan yang berhubungan dengan warga negaranya. Terlebih negara yang memiliki jumlah penduduk yang besar seperti Indonesia. Masalah pengangguran, ketenagakerjaan, kenaikan harga (inflasi) dan kemiskinan di Indonesia sudah menjadi masalah pokok dan membutuhkan solusi yang tepat untuk menyelesaikan permasalahan tersebut agar tidak menghambat langkah Negara Indonesia menjadi Negara Maju.

Indonesia sendiri memiliki solusi untuk menangani masalah kemiskinan yang sedang melanda di berbagai daerah di Indonesia. Program Keluarga Harapan (PKH) merupakan salah satu solusi yang ditawarkan oleh pihak Pemerintah untuk membantu mengurangi angka kemiskinan di setiap daerah di Indonesia. Program ini dianggap sebagai cara yang efektif dalam pengentasan kemiskinan.

Program Keluarga Harapan (PKH) adalah program pemberian bantuan sosial bersyarat kepada Keluarga Miskin (KM) yang ditetapkan sebagai keluarga penerima manfaat PKH. Sebagai upaya percepatan penanggulangan kemiskinan, sejak tahun 2007 Pemerintah Indonesia telah melaksanakan PKH.

Disamping itu, pihak pemerintah khususnya Kemensos juga membuat rancangan usaha berbasis E-Warong KUBE (Kelompok Usaha Bersama) untuk mempercepat pengentasan kemiskinan. E-Warong KUBE menjadi salah satu wadah bagi Keluarga Penerima Manfaat (KPM) untuk menjalankan usaha bersama yang nantinya dapat membantu meningkatkan kesejahteraan Keluarga Penerima Manfaat dari segi ekonomi.

Namun, dibeberapa daerah di Indonesia masih ada yang belum memanfaatkan program ini secara maksimal. Kecamatan Padangsidimpuan Tenggara yang merupakan salah satu Kecamatan yang terdapat di Kota Padangsidimpuan misalnya. Pengadaan E-Warong KUBE di Kecamatan ini terdapat di tiga lokasi yaitu, Desa Salambue, Desa Huta Koje, dan Desa Labuhan Rasoki. Tercatat masih belum memberikan dampak yang begitu besar terhadap perkembangan ekonomi masyarakat. Walaupun sebenarnya masih terdapat banyak peluang yang bisa dimanfaatkan. Sehingga bisa dikatakan bahwa pengadaan E-Warong KUBE ini masih kurang maksimal.Tujuan penelitian ini adalah untuk mengevaluasi pelaksanaan E-Warong KUBE PKH di Kecamatan Padangsidipuan Tenggara.

\section{KAJIAN TEORITIS}

\section{Evaluasi}

Evaluasi merupakan suatu alat atau prosedur yang digunakan untuk mengetahui dan mengukur sesuatu dalam suasana dengan cara dan aturan-aturan yang sudah ditentukan. Dari hasil evaluasi biasanya diperoleh tentang atribut atau sifat-sifat yang terdapat pada JISFIM: Journal of Islamic Social Finance Management, Volume 1, No 2 Tahun 2020 http://jurnal.iain-padangsidimpuan.ac.id/index.php/JISFIM 
individu atau objek yang bersangkutan. Selain menggunakan tes, data juga dapat dihimpun dengan menggunakan angket, observasi, dan wawancara atau bentuk instrumen lainnya yang sesuai. Sedangkan menurut Brinkerhoff dalam Sawitri, evaluasi adalah penyelidikan (proses pengumpulan informasi) yang sistematis dari berbagai aspek pengembangan program profesional dan pelatihan untuk mengevaluasi kegunaan dan kemanfaatannya (Agustanico 2017).

Dalam penelitian ini, model evaluasi yang digunakan yaitu model evaluasi William Dunn yang mengatakan bahwa evaluasi dapat disamakan dengan penaksiran (appraisal), pemberian angka (rating), dan penilaian (assesment). Evaluasi berhubungan dengan produksi informasi mengenai nilai atau manfaat hasil kebijakan dan memberi informasi yang dapat dipercaya mengenai kinerja sebuah kebijakan. Dengan demikian, walaupun evaluasi berkenaan dengan keseluruhan proses kebijakan, evaluasi kebijakan lebih berkenaan dengan kinerja dari kebijakan terutama dalam hal implementasi kebijakan publik. Kriteria evaluasi kebijakan meliputi:

Tabel 1

Tipe Evaluasi Dunn

\begin{tabular}{|c|l|l|}
\hline $\begin{array}{c}\text { Tipe } \\
\text { Kriteria }\end{array}$ & \multicolumn{1}{|c|}{ Pertanyaan } & \multicolumn{1}{|c|}{ Ilustrasi } \\
\hline Efektivitas & $\begin{array}{l}\text { Apakah hasil yang } \\
\text { diinginkan telah dicapai }\end{array}$ & Unit pelayanan \\
\hline Efisiensi & $\begin{array}{l}\text { Seberapa banyak usaha } \\
\text { diperlukan unak } \\
\text { mencapai hasil yang } \\
\text { diinginkan }\end{array}$ & $\begin{array}{l}\text { Unit biaya, } \\
\text { manfaat bersih, } \\
\text { rasio cost- } \\
\text { benefit }\end{array}$ \\
\hline Kecukupan & $\begin{array}{l}\text { Seberapa jauh pencapaian } \\
\text { hasil yang diinginkan } \\
\text { memecahkan masalah }\end{array}$ & $\begin{array}{l}\text { Biaya tetap } \\
\text { efektivitas tetap }\end{array}$ \\
\hline Perataan & $\begin{array}{l}\text { Apakah biaya manfaat } \\
\text { didistribusikan dengan } \\
\text { merata kepada kelompok- } \\
\text { kelompok yang berbeda }\end{array}$ & $\begin{array}{l}\text { Kriteria Pareto, } \\
\text { Kriteria Kaldor- } \\
\text { Hicks, Kriteria } \\
\text { Rawis }\end{array}$ \\
\hline Responsivitas & $\begin{array}{l}\text { Apakah hasil kebijakan } \\
\text { memuaskan kebutuhan, } \\
\text { preferensi, atau nilai } \\
\text { kelompok tertentu }\end{array}$ & $\begin{array}{l}\text { Konsistensi } \\
\text { dengan survai } \\
\text { warganegara }\end{array}$ \\
\hline Ketepatan & $\begin{array}{l}\text { Apakah hasil (tujuan) yang } \\
\text { diinginkan benar-benar } \\
\text { berguna atau bernilai }\end{array}$ & $\begin{array}{l}\text { Program publik } \\
\text { harus merata } \\
\text { dan efisien }\end{array}$ \\
\hline
\end{tabular}

Sumber: Nugroho (2017: 785-786) 


\section{Pelaksanaan}

Pelaksanaan adalah suatu tindakan atau pelaksanaan dari sebuah rencana yang sudah disusun secara matang dan terperinci, implementasi biasanya dilakukan setelah perencanaan sudah dianggap siap. Secara sederhana pelaksanaan bisa diartikan penerapan. Majone dan Wildavsky mengemukakan pelaksanaan sebagai evaluasi. Browne dan Wildavsky mengemukakan bahwa pelaksanaan adalah perluasan aktivitas yang saling menyesuaikan (Nurdin Usman 2002).

\section{E-Warong KUBE PKH}

Program E-Warong KUBE PKH merupakan metode yang digunakan untuk mengimplementasikan Peraturan Menteri Sosial No. 25 Tahun 2016 Tentang Kelompok Usaha Bersama. Dalam peraturan Menteri dijelaskan bahwa, Kelompok Usaha Bersama yang selanjutnya disebut KUBE adalah kelompok keluarga miskin yang dibentuk, tumbuh dan berkembang atas prakarsanya dalam melaksanakan usaha ekonomi produktif untuk meningkatkan pendapatan keluarga (undang-undang Permensos 2016).

\section{Kementerian Sosial}

Kementerian sosial adalah kementerian yang mempunyai tugas menyelenggarakan dan membidangi urusan dalam negeri di dalam pemerintahan untuk membantu presiden dalam penyelenggaraan pemerintahan negara di bidang sosial.

\section{Keluarga Penerima Manfaat (KPM) PKH}

Tujuan Keluarga Penerima Manfaat yaitu:

a. Untuk meningkatkan taraf hidup Keluarga Penerima Manfaat melalui akses layanan pendidikan, kesehatan, dan kesejahteraan sosial

b. Mengurangi beban pengeluaran dan meningkatkan pendapatan keluarga miskin dan rentan

c. Menciptakan perubahan perilaku dan kemandirian Keluarga Penerima Manfaat dalam mengakses layanan kesehatan dan pendidikan serta kesejahteraan sosial

d. Mengurangi kemiskinan dan kesenjangan, dan Mengenalkan manfaat produk dan jasa keuangan formal kepada Keluarga Penerima Manfaat.

Dalam pembahasan ini, sasaran $\mathrm{PKH}$ merupakan keluarga yang miskin dan rentan serta terdaftar dalam data terpadu program penanganan fakir miskin, memilliki komponen kesehatan, pendidikan, dan atau kesejahteraan sosial.

\section{METODE PENELITIAN}

Penelitian ini dilaksanakan di E-Warong KUBE PKH di Kecamatan Padangsidimpuan Tenggara yang terdiri dari 3 desa yaitu, Desa Salambue, Desa Huta Koje dan Desa Labuhan Rasoki. Jumlah sampel dalam penelitian ini yaitu 9 informan. Teknik pengambilan sampel JISFIM: Journal of Islamic Social Finance Management, Volume 1, No 2 Tahun 2020 http://jurnal.iain-padangsidimpuan.ac.id/index.php/JISFIM 
yang digunakan yaitu teknik Purposive sampling. Purposive sampling adalah penarikan sampel yang dilakukan dengan cara mengambil subjek didasarkan pada tujuan tertentu (Amiruddin \& Zainal Asikin 2018).

Adapun teknik pengumpulan data yang digunakan dalam penelitian ini adalah observasi lapangan, wawancara dan dokumentasi. Nasution menyatakan bahwa, observasi adalah dasar semua ilmu pengetahuan (Sugiyono 2016). Jenis wawancara dalam penelitian ini adalah wawancara terstruktur. Wawancara terstruktur adalah wawancara yang pewawancaranya menetapkan sendiri masalah dan pertanyaan-pertanyaan yang akan diajukan. Penggunaan jenis wawancara ini bertujuan mencari jawaban atas hipotesis. Semua subjek dipandang mempunyai kesempatan yang sama untuk menjawab pertanyaan yang diajukan (Lexy J. Moeleong 2013). Dokumentasi merupakan catatan peristiwa yang sudah berlalu. Dokumentasi bisa berbentuk tulisan, gambar, atau karya-karya monumental dari seseorang. Dokumen yang berbentuk tulisan misalnya catatan harian, sejarah kehidupan, biografi, peraturan dan kebijakan (Sugiyono 2012).

Teknik analisis data dalam penelitian ini dilakukan dengan cara analisis data, penyajian data dan penarikan kesimpulan. Teknik pengecekan keabsahan data dilakukan dengan peroanjangan keikutsertaan, ketekunan pengamatan dan triangulasi. Dalam penelitian ini bentuk triangulasi yang digunakan yaitu triangulasi sumber yang dilakukan dengan cara mengecek informasi/data yang diperoleh melalui wawancara dengan informan. Kemudian data tersebut ditanyakan kepada informan lain yang masih terkait satu sama lain, penggunaan metode triangulasi ini dilakukan untuk mendapatkan jawaban yang lebih jelas.

\section{HASIL DAN PEMBAHASAN}

Pada dasarnya program E-Warong KUBE PKH adalah sarana usaha yang didirikan dan dikelola oleh Kube Jasa sebagai sarana pencairan Bantuan Sosial berupa bahan pangan pokok dan/atau uang tunai secara elektronik, kebutuhan usaha, serta pemasaran hasil produksi anggota Kube. Tujuannya ialah untuk meningkatkan kesejahteraan keluarga penerima manfaat Bantuan Sosial (undang-undang Permensos 2016).

Di Kota Padangsidimpuan sendiri, di Kecamatan Padangsidimpuan Tenggara terdapat 3 Desa yang memiliki usaha E-Warong KUBE PKH ini, yaitu Desa Salambue, Desa Hutakoje dan Desa Labuhan Rasoki. Dari ketiga desa ini belum terdapat perubahan yang signifikan mengenai tujuan pelaksanaan dari E-Warong KUBE PKH itu sendiri, program yang dijalankan belum maksimal sesuai dengan petunjuk pelaksanaan E-Warong KUBE PKH. 


\section{Pembahasan}

\section{Pelaksanaan E-Warong KUBE PKH Di Kecamatan Padangsidimpuan Tenggara}

Pelaksana dan pengelola E-Warong KUBE penanganan fakir miskin perkotaan adalah anggota KUBE jasa, yang anggotanya berasal dari peserta PKH dan penerima Raskin/Rastra ditetapkan oleh Dinas Sosial Kab/Kota.

Dalam penelitian ini peneliti akan membahas mengenai pelaksanaan E-Warong KUBE PKH di Kecamatan Padangsidimpuan Tenggara sesuai dengan petunjuk pelaksanaan. Adapun petunjuk pelaksanaan diuraikan sebagai berikut:

1. Melayani pencairan bantuan sosial nontunai

2. Melayani bahan pangan pokok murah bagi penerima bantuan sosial

3. Melayani pembayaran telepon, listrik dan air bagi penerima bantuan sosial dan masyarakat umum

4. Memasarkan hasil produksi KUBE

5. Menjadi agen bank yang bekerjasama dalam penyaluran bantuan sosial nontunai

6. Melakukan usaha pengemasan ulang bahan pangan pokok dari bentuk curah menjadi kemasan tertentu

Program ini dimaksudkan sebagai upaya untuk penurunan angka kemiskinan yang telah direncanakan sebelumnya. Program ini menawarkan suatu program yang dinamakan E-Warong KUBE sebagai bentuk bantuan kepada masyarakat miskin.

\section{Desa Salambue}

Pihak Kemensos memberikan arahan kepada Desa Salambue untuk mendirikan EWarong KUBE PKH yang diberi nama E-Warong KUBE Serasi yang berdiri pada tahun 2017, namun mulai aktif pada tahun 2018.

Pelaksanaan Program E-Warong KUBE di Kecamatan Padangsidimpuan Tenggara khususnya di Desa Salambue secara teknis sudah memenuhi standar petunjuk pelaksana, namun secara pengaplikasian di lapangan belum sesuai dengan pencapaian yang diinginkan. Berdasarkan data yang diperoleh peneliti dilapangan bahwa pelaksanaan E-Warong KUBE PKH di Desa Salambue belum terlaksana dengan maksimal.

\section{Desa Hutakoje}

Pihak Kemensos memberikan arahan kepada Desa Huta Koje untuk mendirikan EWarong KUBE PKH yang diberi nama E-Warong KUBE Melati yang berdiri pada tahun 2017, namun mulai aktif pada tahun 2018.

Selain Desa Salambue, Desa Huta Koje juga termasuk Desa yang diberikan kesempatan untuk pengadaan E-Warong KUBE di tengah-tengah masyarakat, dimana pelaksanaan program E-Warong jika dilihat secara teknis sudah terlaksana sesuai dengan petunjuk pelaksanaan program E-Warong KUBE, akan tetapi dalam pengaplikasiannya secara nyata http://jurnal.iain-padangsidimpuan.ac.id/index.php/JISFIM 
belum terealisasikan sesuai dengan hasil observasi yang dilakukan peneliti bahwa tidak semua anggota PKH mampu mengaplikasikan program sesuai dengan petunjuk pelaksanaan E-Warong KUBE PKH.

Berdasarkan data yang diperoleh peneliti di lapangan, bahwa di Desa Hutakoje pelaksanaan E-Warong KUBE PKH belum dilaksanakan secara maksimal sesuai dengan petunjuk pelaksanaan E-Warong KUBE PKH.

\section{Desa Labuhan Rasoki}

Pihak Kemensos memberikan arahan kepada Desa Labuhan Rasoki untuk mendirikan E-Warong KUBE PKH yang diberi nama E-Warong KUBE Bersama yang berdiri pada tahun 2017, namun mulai aktif pada tahun 2018.

Desa Labuhan Rasoki juga merupakan desa yang diberikan amanah untuk menjalankan program E-Warong KUBE PKH, sama halnya dengan Desa Salambue dan Desa Huta Koje, hadirnya E-Warong KUBE PKH memberikan dampak yang begitu baik khususnya kepada anggota $\mathrm{PKH}$, karena dengan adanya program ini, anggota $\mathrm{PKH}$ terbantu dari segi ekonomi, biaya anak sekolah, dan untuk memenuhi kebutuhan sehari-harinya. Namun jika dilihat dari segi pengaplikasiannya, program E-Warong KUBE PKH di Desa ini belum maksimal dilakukan.

Berdasarkan data yang diperoleh peneliti di lapangan, bahwa di Desa Labuhan Rasoki pelaksanaan E-Warong KUBE PKH belum dilaksanakan secara maksimal sesuai dengan petunjuk pelaksanaan E-Warong KUBE PKH.

\section{Evaluasi Terhadap Pelaksanaan E-Warong KUBE PKH di Kecamatan Padangsidimpuan Tenggara}

Pembahasan hasil penelitian ini merupakan penafsiran terhadap hasil akhir dalam melakukan pengujian data dengan teori dan konsep para ahli sehingga bisa mengembangkan teori atau bahkan menemukan teori baru serta mendeskripsikan hasil data dan fakta di lapangan, peneliti dalam hal ini menghubungkan temuan hasil penelitian di lapangan dengan dasar operasional yang telah ditetapkan, dalam hal ini adalah menggunakan teori William Dunn. Setelah melakukan penelitian di lapangan dapat dilihat bahwa hasil evaluasi terhadap pelaksanaan E-Warong KUBE PKH di Kecamatan Padangsidimpuan Tenggara, yaitu sebagai berikut:

\section{Efektivitas}

Efektivitas berkaitan dengan tingkat keberhasilan suatu aktivitas sehingga suatu kegiatan akan dikatakan efektif apabila kegiatan tersebut mempunyai pengaruh besar terhadap kemampuan penyediaan layanan publik, yang tidak lain dalam kaitan pengelolaan E-Warong KUBE dari kebijakan yang telah ditetapkan sebelumnya.

JISFIM: Journal of Islamic Social Finance Management, Volume 1, No 2 Tahun 2020 http://jurnal.iain-padangsidimpuan.ac.id/index.php/JISFIM 
Berdasarkan hasil penelitian, di ketiga desa tersebut target kegiatan pelaksanaan program E-Warong KUBE belum tercapai sesuai dengan tujuan yang diharapkan, karena masih terdapat kejanggalan yang ditinjau dari pelaksanaan program.

\section{Efisiensi}

Efisiensi disini merupakan seberapa banyak usaha yang dilakukan di dalam mencapai hasil yang di inginkan. Dalam hal ini hasil yang diinginkan merupakan nilai wajar tanpa pengecualian yang diberikan oleh pihak Kemensos kepada anggota PKH di Kecamatan Padangsidimpuan Tenggara.Akan tetapi dalam pelaksanaannya masih belum maksimal dilakukan, ketiga desa di Kecamatan Padangsidimpuan Tenggara memiliki kasus yang sama yaitu pernah mengalami kebangkrutan akibat kurang ketelitian dan kurangnya kesadaran terhadap E-Warong sebagai tanggungjawab bersama.

\section{Kecukupan}

Kecukupan disini merupakan suatu nilai dari seberapa jauhnya pencapaian dari sebuah hasil yang diinginkan. Dalam hal ini hasil yang diinginkan merupakan kesesuaian proses kegiatan pelaksanaan program E-Warong KUBE dengan tingkat kebutuhan anggota $\mathrm{PKH}$. Kebijakan yang dikeluarkan pemerintah biasanya mengharapkan suatu perubahan kondisi yang lebih baik dan dapat memenuhi kebutuhan anggota PKH.

Berdasarkan hasil penelitian, bahwa pengadaan program E-Warong KUBE memberi manfaat bagi anggota $\mathrm{PKH}$, karena di warung ini para anggota $\mathrm{PKH}$ dapat memenuhi kebutuhan sehari-hari dengan harga yang lebih murah dibandingkan dengan warung lain, hal ini disebabkan karena harga di E-Warong KUBE hampir sama dengan harga grosir.

\section{Perataan}

Perataan berkaitan dengan bagaimana suatu kebijakan yang dibuat dan dilaksanakan dapat terdistribusikan pelayanannya atas dasar kriteria kesamaan manfaat yang diberikan. Pihak Kemensos dalam pencairan dana untuk pendirian E-Warong KUBE di setiap desa tidak memiliki perbedaan, dana dialokasikan dan disamakan sesuai dengan kebutuhan dalam pendirian warung tersebut.

Berdasarkan hasil penelitian, bahwa anggaran dana yang diberikan pihak Kemensos kepada anggota PKH untuk masing-masing desa di Kecamatan Padangsidimpuan Tenggara sudah dibagi sama rata tanpa dibeda-bedakan.

\section{Responsifitas}

Responsifitas berkenaan dengan seberapa jauh suatu kebijakan dapat memuaskan dan memenuhi kebutuhan, preferensi, atau nilai kelompok masyarakat tertentu.

Berdasarkan hasil penelitian, bahwa respon masyarakat terhadap E-Warong KUBE kurang memberikan dukungan untuk memajukan warung, namun terdapat juga beberapa yang mendukung, hal tersebut dikuatkan dengan hasil penelitian yaitu mengatakan bahwa 
masyarakat juga ada yang berbelanja di warung tersebut, yang berarti ada beberapa masyarakat juga yang merasa terbantu dalam memenuhi kebutuhannya karena mengingat harga yang relatif murah.

\section{Ketepatan}

Ketepatan berkenaan dengan seberapa jauh (tujuan) yang diinginkan benar-benar berguna atau bernilai. Proses pelaksanaan E-Warong KUBE diharapkan mampu memberikan manfaat kepada anggota $\mathrm{PKH}$ dan juga berguna bagi masyarakat umum.

Berdasarkan hasil penelitian, bahwa dana yang diberikan pihak Kemensos dipakai seluruhnya untuk pelaksanaan program E-Warong KUBE berupa pembangunan warung, serta melengkapi sarana dan prasarana. Berdasarkan hasil penelitian, untuk pemberdayaan anggota PKH terhadap warung dinyatakan kurang maksimal yang menyebabkan warung tersebut belum berkembang.

\section{KESIMPULAN}

Berdasarkan hasil penelitian dan pembahasan, maka dapat ditarik kesimpulan mengenai "Evaluasi Terhadap Pelaksanaan E-Warong KUBE PKH di Kecamatan Padangsidimpuan Tenggara” pada poin menghapus masalah kemiskinan sesuai dengan 2 fokus penelitian. Pencapaian hasil pelaksanaan E-Warong KUBE PKH di Kecamatan Padangsidimpuan Tenggara masih belum maksimal dirasakan sesuai dengan petunjuk pelaksanaan E-Warong KUBE PKH. Berdasarkan teori William Dunn adalah efektivitas target pelaksanaan, efisiensi usaha yang dilakukan untuk mencapai hasil yang dinginkan, dan ketepatan tujuan yang diinginkan benar-benar berguna dan bermanfaat sudah maksimal dilakukan. Sedangkan kecukupan pencapaian dari hasil yang diinginkan, perataan kebijakan yang dibuat untuk pencapaian target pelaksanaan, dan responsifitas suatu kebijakan dapat memenuhi kebutuhan masyarakat miskin belum maksimal.

\section{DAFTAR PUSTAKA}

Agustanico, Muryadi. 2017. "MODEL EVALUASI PROGRAM DALAM PENELITIAN EVALUASI.” Universitas Tunas Pembangunan Surakarta. https://doi.org/10.1017/CBO9781107415324.004.

Amiruddin \& Zainal Asikin. 2018. Pengantar Metode Penelitian Hukum. Jakarta: Raja Grafindo Persada.

Lexy J. Moeleong. 2013. Metode Penelitian Kualitatif. Bandung: PT Remaja Rosda Karya. Nurdin Usman. 2002. Konteks Implementasi Berbasis Kurikulum. Jakarta: PT Raja Grafindo Persada.

Sugiyono. 2012. Metode Penelitian Bisnis (Pendekatan Kuantitatif, Kualitatif, Dan R\&D). Bandung: Alfabeta.

---. 2016. Metode Penelitian Bisnis. Bandung: Alfabeta.

undang-undang Permensos. 2016. No Title.

JISFIM: Journal of Islamic Social Finance Management, Volume 1, No 2 Tahun 2020 http://jurnal.iain-padangsidimpuan.ac.id/index.php/JISFIM 